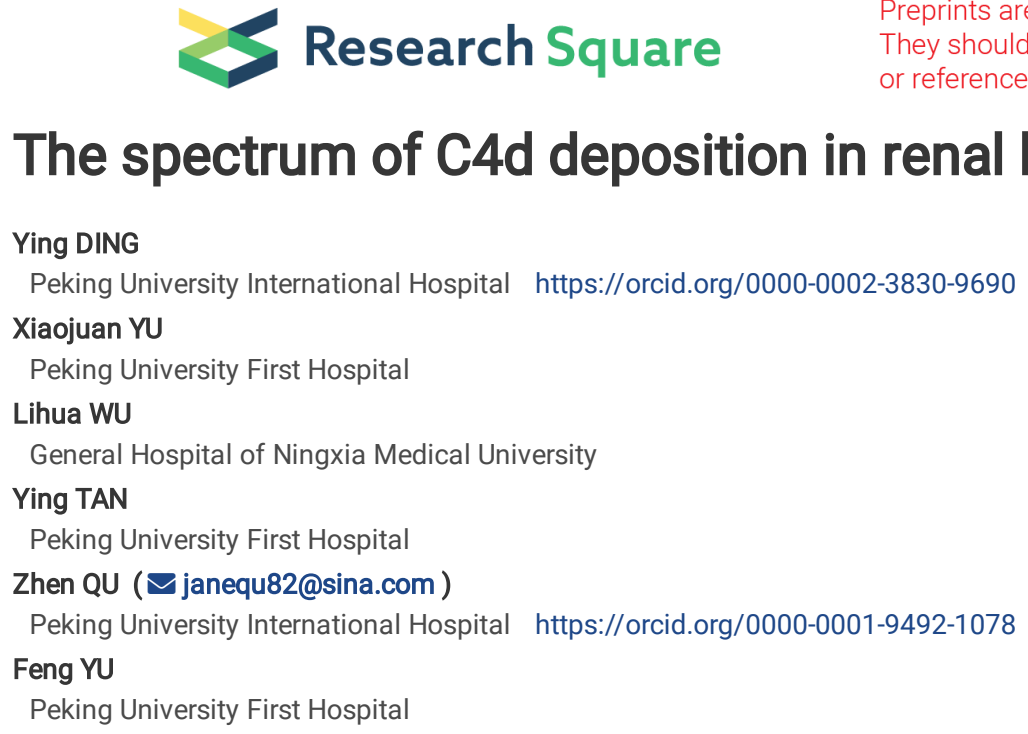

\title{
The spectrum of C4d deposition in renal biopsies of lupus nephritis patients
}

\section{Research}

Keywords: C4d, lupus nephritis, renal microvascular lesions

Posted Date: December 15th, 2020

DOI: https://doi.org/10.21203/rs.3.rs-126613/v1

License: (c) (1) This work is licensed under a Creative Commons Attribution 4.0 International License. Read Full License 


\section{Abstract \\ Objectives}

This study aims to determine the prevalence and localization of complement factor C4d in renal biopsies of lupus nephritis (LN) patients, as well as its association with the clinico-pathological features of the disease. Especially, the correlation between arteriolar C4d deposition and renal microvascular lesions (RVL) was further analyzed.

\section{Methods}

A total of 325 biopsy-proven lupus nephritis patients were enrolled and their clinico-pathological data were collected. C4d staining in renal biopsies was performed by immunohistochemistry. The association between $\mathrm{C} 4 \mathrm{~d}$ deposition and the clinico-pathological features was further analyzed.

\section{Results}

C4d deposition was present in most of renal specimens (98.8\%) in our cohort. They were localized in the glomeruli (98.2\%), tubular basement membrane (TBM) (43.7\%), arterioles (31.4\%) and peritubular capillary (33.8\%), respectively. TBM C4d staining was closely related to the disease activity (SLEDAI) and $\mathrm{NIH}$ pathological activity and chronicity indices $(P<0.01)$. Patients with arteriolar C4d deposition were more likely to develop RVL $(91.2 \%)$ in comparison to those negative (78.0\%; $P=0.004)$, especially with two or more types of RVL $(P<0.001)$. During an average follow-up of 55.8 months, the presence of arteriolar C4d was related to worse renal outcomes (HR: 2.074, 95\% Cl 1.056-4.075, $P=0.034$ ). Co-deposition of arteriolar C4d and C3c was an independent risk factor (HR: $2.539,95 \% \mathrm{Cl} 1.130-5.705, P=0.024)$ for predicting renal outcomes by the multivariate stepwise Cox hazard analysis

\section{Conclusions}

C4d deposition was common in renal tissues of lupus nephritis patients. TBM C4d deposition was related to the disease activity and arteriolar C4d deposition was associated with RVL and worse renal outcomes.

\section{Background}

Systemic lupus erythematous (SLE) is an autoimmune disease with a wide variety of clinical manifestations and serological abnormalities(1). Lupus nephritis (LN) presented in up to $60 \%$ of the SLE patients during the disease course(2), which contributed to the morbidity and mortality of the disease. Renal histopathology was in close relation with its clinical characteristics, responses to the treatment and prognosis of the lupus nephritis patients(3).

Complement activation plays a key role in the pathogenesis of lupus nephritis(4). Classical pathway was thought to be the dominant pathway for complement activation in lupus nephritis, triggered by the interaction of C1q with immune complex(5). Mannose-binding lectin (MBL) could also be detected in the glomeruli of lupus nephritis patients by several studies(6,7), implicating its participation.

C4d, a fragment of C4 generated during activation of the complement pathway, is regarded as a footprint of the classical or lectin complement pathway activation (8). Its deposition in renal peritubular capillaries (PTC) has already been widely accepted as a maker of antibody-mediated rejection (AMR) in transplanted kidneys $(9,10)$. Its meaning in other kidney diseases like lupus nephritis in which many different autoantibodies produced an analogous situation has also been investigated in recent years. The deposition of C4d on PTC could be observed in lupus nephritis patients, but with a different pattern from those observed in antibody-mediated renal rejection, which was closely related to the disease activity(11-13). Besides, KIM SH et al found that glomerular C4d deposition could be detected in the majority of the lupus nephritis cases, but not a marker for lupus nephritis activity(14). However, another study conducted by Cohen $\mathrm{D}$ et al demonstrated that lupus nephritis patients with prominent diffuse glomerular C4d deposition had more chance to develop renal thrombotic microangiopathy (TMA) lesion than patient with focal or mild C4d staining(15). Thus, the role of C4d deposition, especially in the different areas of renal biopsies in lupus nephritis, remained to be further clarified.

Herein, we aim to assess the comprehensive prevalence and anatomic localization of C4d deposition in renal biopsy specimens based on a well-defined lupus nephritis cohort. Their clinical significances were further analyzed.

\section{Methods}

\section{Patients}

Clinical and renal histopathological data of 325 patients with renal biopsy proven lupus nephritis, diagnosed between January 2000 and June 2008 from Peking University First Hospital, were enrolled. All the patients included fulfilled the 1997 American College of Rheumatology revised criteria for SLE(16). Patients with less than 10 glomeruli and 6 vessels in renal biopsies were excluded. Informed consent was obtained for blood sampling and renal biopsy from each patient. The research was in compliance with the Declaration of Helsinki. The design of this work was approved by the local ethical committees of Peking University First Hospital (No. 2017 (1333)).

\section{Clinical evaluation}


The disease activity was assessed by the Systemic Lupus Erythematous Disease Activity Index (SLEDAI)(17, 18). All the patients were followed up in outpatient clinics specified for lupus nephritis. The primary end point was defined as death, and the secondary end point was defined as end stage renal disease (ESRD) or doubling of serum creatinine value.

\section{Laboratory assessment}

Serum antinuclear antibodies (ANA) were detected using the indirect immunofluorescence assay (EUROIMMUN, Lübeck, Germany). Anti-double-stranded DNA (anti-dsDNA) antibodies were detected using the Crithidia luciliae indirect immunofluorescence test (EUROIMMUN, Lübeck, Germany). Serum C3 was determined using the rate nephelometry assay (IMMAGE; Beckman-Coulter, IMMAGE, Fullerton, CA; normal range $>0.85 \mathrm{~g} / \mathrm{l}$ ).

\section{Renal histopathology}

The renal biopsy specimens were routinely examined by light microscopy, direct immunofluorescence and electron microscopy techniques. Lupus nephritis was classified according to the International Society of Nephrology and Renal Pathology Society (ISN/RPS) 2003 lupus nephritis classification system(19). Especially, renal microvascular lesions were classified according to the previous work as the followings ${ }^{(20)}$ )(21): immune complex deposits (ICD), noninflammatory necrotizing vasculopathy (NNV), thrombotic microangiopathy (TMA), true renal vasculitis (TRV) and atherosclerosis (AS). The semiquantitative scores of the renal microvascular lesions were determined according to our previous work(21).

\section{C4d, C1q, C3c and immunoglobulins staining on kidneys}

Staining of C4d on formalin-fixed paraffin-embedded tissue (4- $\mu \mathrm{m}$ thick) was performed by immunohistochemistry. Rabbit anti-human C4d polyclonal antibodies (Abcam, Cambridge, UK) were used as primary antibodies. Glomerular C4d staining (G-C4d) was graded as negative ( $0 \%$ ), minimal ( $1,<10 \%$ of glomeruli), focal $(2,10-50 \%$ of glomeruli) and diffuse $(3,>50 \%$ of glomeruli) based on the distribution of the staining. The intensity of G-C $4 \mathrm{~d}$ was also semiquantitatively graded $(0-3)(12,22)$. Tubular basement membrane (TBM) C4d (TBM-C4d) was considered to be present if more than half of the individual TBM circumference was stained. It was then graded as negative ( $0 \%)$, minimal $(1,<10 \%$ of tissue specimen), focal $(2,10-50 \%$ of tissue specimen) and diffuse ( 3 , $>50 \%$ of tissue specimen $)(12,22)$. PTC-C4d staining was graded in accordance with the Banff 2007 criteria for C4d staining as negative $(0 \%)$, minimal $(1$, $<10 \%$ of tissue specimen), focal ( $2,10-50 \%$ of tissue specimen) and diffuse ( $3,>50 \%$ of tissue specimen)(23). Arteriolar C4d staining (A-C4d) were semiquantitatively graded as negative ( $0 \%)$, minimal $(1,<10 \%$ of tissue specimen), focal $(2,10-50 \%$ of tissue specimen) and diffuse ( $3,>50 \%$ of tissue specimen) $(12,24)$. Negative control experiments were performed by omitting or replacing the primary antibodies. The typical presentations of $\mathrm{C} 4 \mathrm{~d}$ staining in different areas of kidneys were shown in Figure 1.

The fresh frozen tissue sections were stained immediately after the renal biopsy with fluorescein isothiocyanate-labeled rabbit anti-human IgG, IgA, IgM, C3c and C1q antibodies (Dako A/S, Copenhagen, Denmark). The results were graded from 0 to 4 according to the intensity of fluorescence.

\section{Statistical analysis}

Statistical software SPSS 18.0 (SPSS, Chicago, IL, USA) was used for statistical analysis. Quantitative data were expressed as mean \pm s.d. and as median with range (minimum and maximum). The Spearman's rank-order correlation test was performed between various lesions. Differences in semiquantitative data were tested with the Kruskal-Wallis test and the Mann-Whitney U-test. Kaplan-Meier curves were used to analyze patients' prognosis. Univariate survival analysis was carried out using the log-rank test. The Cox regression model was applied to identify prognostic factors associated with renal outcomes. Results were expressed as hazard ratio with $95 \%$ confidence intervals. Statistical significance was considered at $P<0.05$.

\section{Results}

\section{Baseline data of the lupus nephritis cohort}

A total of 325 lupus nephritis patients were enrolled. Their clinico-pathological data were descripted in Table 1.

The average follow-up time was 55.8 months (range from 4 to 360 months). During the follow-up period, 3 patients died of heart failure and 1 patient died of severe infection. 37 patients reached secondary end point, including 35 with end-stage renal disease and 2 with doubling of serum creatinine value.

\section{The prevalence and localization of C4d staining in renal specimens of lupus nephritis patients (Table 2)}

The C4d staining was present in 321 of the total 325 LN samples (98.8\%). They were localized in the glomerulus (319 of $325,98.2 \%)$, tubular basement membrane (TBM) (142 of $325,43.7 \%)$, arterioles (102 of $325,31.4 \%$ ) or peritubular capillaries (PTC) $(110$ of $325,33.8 \%)$ respectively.

The presence and intensity of C4d staining among different sub-classes of lupus nephritis were described in Figure 2. We found that the ratio of TBM C4d deposition significantly differed among the subtypes $(P<0.001)$, and it was more often present in class III, IV and V group than class II group. The ratio of glomerular, arteriolar and PTC C4d deposition did not reach statistical difference among them.

\section{Correlation between C4d deposition and clinico-pathological data}

The detailed analysis between C4d deposition in different renal areas and clinical and laboratory features were shown in Table 3. Of note, the deposition of C4d in the TBM area was significantly correlated with the disease activity (SLEDAl) $(r=0.190, P<0.01)$, hematuria $(r=0.134, P<0.05)$, leukocyturia ( $\mathrm{r}=0.177$, $P<0.01)$, urine protein level $(\mathrm{r}=0.177, P<0.01)$, acute kidney injury $(\mathrm{r}=0.183, P<0.05)$, serum creatinine value $(\mathrm{r}=0.288, P<0.01)$ and serum $\mathrm{C} 3$ level $(\mathrm{r}=-0.149$, $P<0.01)$ 
Renal histopathological findings showed that C4d deposition in TBM, arterioles and PTC were positively correlated to several NIH activity indices (Al) and chronic indices $(\mathrm{Cl})$, respectively (Table 4).

\section{Association between arteriolar C4d (A-C4d) deposition and renal microvascular lesions in lupus nephritis patients}

As renal microvascular lesions were common in lupus nephritis, the role of arteriolar C4d (A-C4d) deposition in renal microvascular lesions (RVL) was especially explored. In our study, 267 (82.2\%) patients presented with RVL. Among them, 34.8\% patients had A-C4d deposition, much higher than those without RVL $(15.5 \%, P=0.004)$. In parallel, those with A-C4d deposition were more likely to develop RVL ( $91.2 \%)$ in comparison to those negative $(78.0 \%$; $P=0.004)$, especially in the subgroup with two or more types of RVL $(P<0.001)$ (Figure 3$)$. Moreover, diffuse $(>50 \%)$ or focal (10-50\%) renal A-C4d staining pattern was more common in patients with RVL ( $\mathrm{n}=22$ of 267 [8.2\%]) compared with those negative ( $\mathrm{n}=2$ of 58 [3.4\%]; $P=0.035)$.

As to the subtypes of RVL, the patients with TMA lesion had the highest ratio of A-C4d deposition (48.3\%), followed by patients with ICD (38.3\%), NNV (38.5\%) and AS (34.5\%).

Analysis of co-depositions of A-C4d and C1q, C3c and different immunoglobulins were further analyzed. Patients with A-C4d deposits had higher ratios of C1q deposition (75.5\% VS 59.2\%, $P=0.004)$, C3c deposition (39.2\% VS 28.7\%, $P=0.059)$, IgG deposition (40.2\% VS 29.1\%, $P=0.049)$, IgM deposition (37.3\% VS $25.6 \%, P=0.031)$ and IgA deposition (17.6\% VS 7.2\%, P=0.004), respectively than those negative. As shown in Table 5 , patients with both C4d and C3c staining had significantly higher scores of $\mathrm{Cl}(P=0.024)$, tubular atrophy $(P=0.049)$ and interstitial fibrosis $(P=0.027)$ than those with solely $\mathrm{C} 4 \mathrm{~d}$ positive. Similar results were also found in $\mathrm{C} 4 \mathrm{~d}+\mathrm{C} 1 \mathrm{q}, \mathrm{C} 4 \mathrm{~d}+\lg \mathrm{G}, \mathrm{C} 4 \mathrm{~d}+\lg \mathrm{M} \mathrm{C} 4 \mathrm{~d}+\lg \mathrm{A}$ double positive groups, respectively.

\section{The C4d deposition and renal outcomes in lupus nephritis}

During the follow-up time, patients with arteriolar $\mathrm{C} 4 \mathrm{~d}$ deposition $(P=0.03)$ presented with worse renal survival rates than those negative (Figure $4 \mathrm{~A})$. C4d deposition in other renal compartments did not influence the renal outcomes of the patients. When the patients were categorized into four groups according to the arteriolar C4d and C3c staining, those with both arteriolar C4d and C3c staining positive had the worst renal outcomes (Figure 4B).

Using the univariate survival analysis of renal prognosis in lupus nephritis, we found that arteriolar C4d (HR 2.074, 95\% $\mathrm{Cl} 1.056-4.075, P=0.034)$ deposition and co-deposition of C4d and C3c were risk factors for renal outcomes (Table 6). With further exploration by multivariate stepwise Cox hazard analysis, we found that C4d deposition was not an independent prognostic predictor, but the co-deposition of C4d and C3c (HR: 2.539, 95\% Cl 1.130-5.705, $P=0.024)$ was identified as an independent risk factor for predicting renal outcomes in lupus nephritis (Table 7).

\section{Discussion}

Complement activation, especially via the classical pathway, is widely accepted to play an important role(25) in the pathogenesis of lupus nephritis(26). C4d is a split of the complement activation that remains covalently bound, long after the complement pathway-initiating factors have dissociated. It could be initiated by immune complex through both the classical pathway and the lectin pathway $(27,28)$ and might play a key role in the pathomechanism of the disease(29). However, there lacked generic descriptions of its distribution in renal biopsies of lupus nephritis in a larger cohort and more detailed analysis of its clinico-pathological significance is needed.

In this study, we found that renal C4d deposition was ubiquitous (98.8\%) in lupus nephritis patients, which was mildly higher than previous ratio ranging from $86.8-92 \%(12,15,30)$. The difference of $\mathrm{C} 4 \mathrm{~d}$ deposition between studies might be attributed to the varied testing methods and the disease activity of the patients enrolled $(12,22)$, like more than half of our patients were of type IV lupus nephritis with a rather high disease activity. Furthermore, we found that the C4d deposition pattern and ratio varied among different renal compartments, reflecting clinico-pathological features. Especially, TBM C4d deposition was better related to the disease activity and a prognostic value of arteriolar C4d deposition was found in lupus nephritis patients.

Glomerular C4d deposition was proved to be common in lupus nephritis in both our study and previous reports(12, 15, 25). Sahin OZ et al suggested that glomerular C4d staining could be an indicator of disease activity in lupus nephritis patients(31). Cohen et al. and Shen $\mathrm{Y}$ et al also described that the intense glomerular C4d staining was an indicator of thrombotic microangiopathy in lupus nephritis $(15,25)$. However, neither its distribution nor its intensity was proved to be related to the disease activity and any microvascular lesion in our study, which concurred with the work by Kim et al and Batal I et al, indicating that its deposition might only be a reflection of in situ classical complement pathway activation induced by immune complex(12, 14).

PTC-C4d deposition was known to be a key marker in the diagnosis of antibody-mediated renal allograft rejection, and it could also be detected in native kidneys(32). Interestingly, a study from China found that PTC-C4d deposited in $6.81 \%$ of the LN patients, which related to the disease activity(13). Although we found a higher rate of C4d deposition in PTC, no significant association between PTC-C4d deposition and the disease activity was confirmed in our study.

Importantly, our findings revealed that lupus nephritis patients with TBM-C4d deposition presented with more severe clinico-pathological features, like a higher dis ease activity, worse renal function, lower complement level, more chance of acute kidney injury and higher $\mathrm{Al}$ and $\mathrm{Cl}$ scores. As the TBM immune complex deposition was closely associated with disease activity and progression of lupus nephritis(33), we proposed that TBM-C4d deposition could reflect the in situ complement activation of the classical or lectin pathway, thus aggravating the local inflammation.

Renal microvascular lesions (RVL) are of great importance in lupus nephritis, which has a prognostic value (21). Previous studies described the arteriolar C4d deposition in TMA cases associated with $\operatorname{SLE}(34,35)$, while the data concerning other RVL type in lupus nephritis was lacked. Our study first observed a close association between arteriolar C4d deposition and different renal microvascular lesions including TMA change. We speculated that some common pathway might be involved in the pathogenesis of RVL, and the fact that a higher ratio of arteriolar C4d deposition in patients with RVL indicated complement might be 
causally involved in its pathogenesis. Interestingly, nearly all the arteriolar C4d positive patients had ICD lesion in our study, and we further stained samples for C1q. As anticipated, $75.5 \%$ of the arteriolar C4d positive patients presented with C1q deposition, which was in keeping with previous studies regarding TMA lesions, in which activation of the classical pathway played a major role(15)'(34). Thus, the complement activation through the classical pathway was suggested to be one of the common pathomechanism involved in various types of RVL. Interestingly, a higher ratio of IgM and IgA deposition was also found in C4d positive patients. Chua JS et al proposed the theory that C4d might also be a consequence rather than reflecting an underlying cause of the damage. Chronic endothelial cell injury may result in the formation of a duplicate glomerular basement membrane, which could entrap aspecific immunoglobulin and C3, and thus mimicking immune complex deposition(34). Moreover, we found that arteriolar C4d positive patients had a higher rate of combined C3c deposition compared to those negative. Both arteriolar C4d and C3c positive patients had the worst renal outcomes. Recent work from Wilson HR found that terminal complement complex (C5b-9) deposition in glomerulus did not differ between active and chronic disease in lupus nephritis(36). In contrast, C3c staining was associated with active disease in lupus nephritis, which would be a better indicator to identify patients who are most likely to benefit from complement inhibiting treatment(36). Thus, local cascade of complement activation might be more likely to be triggered in patients with arteriolar C4d deposition, participating in the progression of the microvascular lesions in the kidney, which indicate an ongoing activity of the disease. So, it might serve as an alternative potential tool to sift out those who might benefit from anti-complement therapy.

\section{Conclusion}

In conclusion, complement factor C4d deposition was common, which varied among different renal compartments in lupus nephritis. TBM-C4d deposition was associated to more severe clinico-pathological features, and arteriolar C4d deposition was closely related with RVL. Further studies are needed to reveal its actual role in the pathomechanism of lupus nephritis.

\section{Abbreviations}

A-C4d: Arteriolar C4d; AMR:Antibody-mediated rejection; Anti-dsDNA:Anti-double-stranded DNA antibodies; ANA:Antinuclear antibody; Al:Activity indices; AS:Atherosclerosis; Cl:Chronic indices; ESRD:End stage renal disease; HR:Hazard ratio; ICD:Immune complex deposits; ISN/RPS:International Society of Nephrology and Renal Pathology Society; LN:lupus nephritis; MBL:Mannose-binding lectin; NIH:National Institutes of Health; NNV:Noninflammatory necrotizing vasculopathy; PTC:Peritubular capillary; RVL:renal microvascular lesions; SLE:Systemic lupus erythematous; SLEDAl:Systemic Lupus Erythematous Disease Activity Index; TBM:Tubular basement membrane; TMA:Thrombotic microangiopathy; TRV:True renal vasculitis.

\section{Declarations}

\section{Fundings}

This work was supported by Grants of National Natural Science Foundation of China (No. 81870479), Pekin University International Hospital Research Grant (No. YN2020QN01, No. YN2020ZD03).

\section{Availability of data and materials}

The datasets used and/or analysed during the current study are available from the corresponding author on reasonable request.

\section{Ethics approval and consent to participate}

All patients included in this work signed a written informed consent form prior to study entry. This study protocol was approved by the Research and Ethics board of the Peking University First Hospital (Approval reference: No. 2017 (1333)). This study followed the recommendations described by the Declaration of Helsinki.

\section{Authors' contribution}

Ying Ding, Lihua Wu, Ying Tan planned the project, selected patients, interpreted results and wrote the paper. Xiaojuan Yu performed analysis of the renal pathology. Zhen Qu, Feng Yu planned the project and revised the paper. All authors read and approved the final manuscript.

\section{Consent for publication}

Not applicable.

\section{Competing interests}

All the authors declare that there are no conflicts of interest to disclose.

\section{References}

1. Rahman A, Isenberg DA. Systemic lupus erythematosus. The New England journal of medicine. 2008;358(9):929-39.

2. Cameron JS. Lupus nephritis. Journal of the American Society of Nephrology : JASN. 1999;10(2):413-24.

3. Appel G, D’Agati R. Secondary glomerular disease. In: Brenner BM (ed). Brenner \& Rector's The Kidney, 8th edn. WBSaunders: Philadephia, 2008; pp 106711462008. 
4. Tang S, Lui SL, Lai KN. Pathogenesis of lupus nephritis: an update. Nephrology. 2005;10(2):174-9.

5. Karp DR. Complement and systemic lupus erythematosus. Current opinion in rheumatology. 2005;17(5):538-42.

6. Lhotta K, Wurzner R, Konig P. Glomerular deposition of mannose-binding lectin in human glomerulonephritis. Nephrology, dialysis, transplantation : official publication of the European Dialysis and Transplant Association - European Renal Association. 1999;14(4):881-6.

7. Sato N, Ohsawa I, Nagamachi S, Ishii M, Kusaba G, Inoshita H, et al. Significance of glomerular activation of the alternative pathway and lectin pathway in lupus nephritis. Lupus. 2011;20(13):1378-86.

8. Berger SP, Roos A, Daha MR. Complement and the kidney: What the nephrologist needs to know in 2006? Nephrol Dial Transpl. 2005;20(12):2613-9.

9. Racusen LC, Colvin RB, Solez K, Mihatsch MJ, Halloran PF, Campbell PM, et al. Antibody-mediated rejection criteria - an addition to the Banff 97 classification of renal allograft rejection. American journal of transplantation : official journal of the American Society of Transplantation and the American Society of Transplant Surgeons. 2003;3(6):708-14.

10. Collins AB, Schneeberger EE, Pascual MA, Saidman SL, Williams WW, Tolkoff-Rubin N, et al. Complement activation in acute humoral renal allograft rejection: diagnostic significance of C4d deposits in peritubular capillaries. Journal of the American Society of Nephrology : JASN. 1999;10(10):2208-14.

11. Mora C, Medina-Rosas J, Santos AM, Jaimes DA, Arbelaez AM, Romero C, et al. Associations of the Levels of C4d-bearing Reticulocytes and High-avidity Anti-dsDNA Antibodies with Disease Activity in Systemic Lupus Erythematosus. The Journal of rheumatology. 2016;43(9):1657-64.

12. Batal I, Liang K, Bastacky S, Kiss LP, McHale T, Wilson NL, et al. Prospective assessment of C4d deposits on circulating cells and renal tissues in lupus nephritis: a pilot study. Lupus. 2012;21(1):13-26.

13. Li SJ, Liu ZH, Zen CH, Wang QW, Wang Y, Li LS. Peritubular capillary C4d deposition in lupus nephritis different from antibody-mediated renal rejection. Lupus. 2007;16(11):875-80.

14. Kim SH, Jeong HJ. Glomerular C4d deposition indicates in situ classic complement pathway activation, but is not a marker for lupus nephritis activity. Yonsei medical journal. 2003;44(1):75-80.

15. Cohen D, Koopmans M, Kremer Hovinga IC, Berger SP, Roos van Groningen M, Steup-Beekman GM, et al. Potential for glomerular C4d as an indicator of thrombotic microangiopathy in lupus nephritis. Arthritis and rheumatism. 2008;58(8):2460-9.

16. Hochberg MC. Updating the American College of Rheumatology revised criteria for the classification of systemic lupus erythematosus. Arthritis and rheumatism. 1997;40(9):1725.

17. Liang MH, Socher SA, Larson MG, Schur PH. Reliability and validity of six systems for the clinical assessment of disease activity in systemic lupus erythematosus. Arthritis and rheumatism. 1989;32(9):1107-18.

18. Bombardier C, Gladman DD, Urowitz MB, Caron D, Chang CH. Derivation of the SLEDAI. A disease activity index for lupus patients. The Committee on Prognosis Studies in SLE. Arthritis and rheumatism. 1992;35(6):630-40.

19. Weening JJ, D'Agati VD, Schwartz MM, Seshan SV, Alpers CE, Appel GB, et al. The classification of glomerulonephritis in systemic lupus erythematosus revisited. Kidney international. 2004;65(2):521-30.

20. Appel GB, Pirani CL, D'Agati V. Renal vascular complications of systemic lupus erythematosus. Journal of the American Society of Nephrology : JASN. 1994;4(8):1499-515.

21. Wu LH, Yu F, Tan Y, Qu Z, Chen MH, Wang SX, et al. Inclusion of renal vascular lesions in the 2003 ISN/RPS system for classifying lupus nephritis improves renal outcome predictions. Kidney international. 2013;83(4):715-23.

22. Batal I, Girnita A, Zeevi A, Saab BA, Stockhausen S, Shapiro R, et al. Clinical significance of the distribution of C4d deposits in different anatomic compartments of the allograft kidney. Modern pathology : an official journal of the United States and Canadian Academy of Pathology, Inc. 2008;21(12):1490-8.

23. Solez K, Colvin RB, Racusen LC, Haas M, Sis B, Mengel M, et al. Banff 07 classification of renal allograft pathology: updates and future directions. American journal of transplantation : official journal of the American Society of Transplantation and the American Society of Transplant Surgeons. 2008;8(4):753-60.

24. Laskin BL, Maisel J, Goebel J, Yin HJ, Luo G, Khoury JC, et al. Renal arteriolar C4d deposition: a novel characteristic of hematopoietic stem cell transplantation-associated thrombotic microangiopathy. Transplantation. 2013;96(2):217-23.

25. Shen Y, Chen XW, Sun CY, Dai M, Yan YC, Yang CD. Association between anti-beta2 glycoprotein I antibodies and renal glomerular C4d deposition in lupus nephritis patients with glomerular microthrombosis: a prospective study of 155 cases. Lupus. 2010;19(10):1195-203.

26. Bomback AS, Markowitz GS, Appel GB. Complement-Mediated Glomerular Diseases: A Tale of 3 Pathways. Kidney international reports. 2016;1(3):148-55.

27. Walport MJ. Complement. First of two parts. The New England journal of medicine. 2001;344(14):1058-66.

28. Walport MJ. Complement. Second of two parts. The New England journal of medicine. 2001;344(15):1140-4.

29. Cohen D, Colvin RB, Daha MR, Drachenberg CB, Haas M, Nickeleit V, et al. Pros and cons for C4d as a biomarker. Kidney international. 2012;81(7):628-39.

30. Martin M, Trattner R, Nilsson SC, Björk A, Zickert A, Blom AM, et al. Plasma C4d Correlates With C4d Deposition in Kidneys and With Treatment Response in Lupus Nephritis Patients. Frontiers in immunology. 2020;11:582737.

31. Sahin OZ, Gurses S, Tasli F, Yavas H, Ersoy R, Uzum A, et al. Glomerular c4d staining can be an indicator of disease activity in lupus nephritis. Renal failure. 2013;35(2):222-5.

32. Colvin RB. Antibody-mediated renal allograft rejection: diagnosis and pathogenesis. Journal of the American Society of Nephrology : JASN. 2007;18(4):1046-56. 
33. Wang H, Xu J, Zhang X, Ren YL, Cheng M, Guo ZL, et al. Tubular basement membrane immune complex deposition is associated with activity and progression of lupus nephritis: a large multicenter Chinese study. Lupus. 2018;27(4):545-55.

34. Chua JS, Baelde HJ, Zandbergen M, Wilhelmus S, van Es LA, de Fijter JW, et al. Complement Factor C4d Is a Common Denominator in Thrombotic Microangiopathy. Journal of the American Society of Nephrology : JASN. 2015;26(9):2239-47.

35. Song D, Wu LH, Wang FM, Yang XW, Zhu D, Chen M, et al. The spectrum of renal thrombotic microangiopathy in lupus nephritis. Arthritis research \& therapy. 2013;15(1):R12.

36. Wilson HR, Medjeral-Thomas NR, Gilmore AC, Trivedi P, Seyb K, Farzaneh-Far R, et al. Glomerular membrane attack complex is not a reliable marker of ongoing C5 activation in lupus nephritis. Kidney international. 2019;95(3):655-65.

\section{Tables}

Table 1. Baseline clinico-pathological data of lupus nephritis patients. 


\begin{tabular}{|c|c|}
\hline Number of patients & 325 \\
\hline Gender (Female/Male) & $271 / 54$ \\
\hline Age $\bigotimes$ mean \pm s.d. $\otimes$ (years) & $32.8 \pm 11.5$ \\
\hline Hypertension, $n(\%)$ (blood pressure $\geqq 140 / 90 \mathrm{mmHg}$ ) & $166(51.1 \%)$ \\
\hline Pleuritis, n(\%) & $55(16.3 \%)$ \\
\hline Neurological disorder, n (\%) & $25(7.7 \%)$ \\
\hline Anemia, $\mathrm{n}(\%)$ & $219(67.4 \%)$ \\
\hline Thrombocytopenia, n(\%) & $104(32.0 \%)$ \\
\hline Hematuria, n(\%) & $249(76.6 \%)$ \\
\hline Acute kidney injury, n(\%) & $67(20.6 \%)$ \\
\hline Urine protein (median and range) (g/24h) & $4.3(0-21.0)$ \\
\hline Serum creatinine value (median and range) $(\mu \mathrm{mmol} / \mathrm{l})$ & $83.0(37.1-971.0)$ \\
\hline C3 (mean \pm s.d.) $(\mathrm{g} / \mathrm{L})$ & $0.48 \pm 0.24$ \\
\hline ANA positivity, $\mathrm{n}(\%)$ & $320(98.5 \%)$ \\
\hline Anti-dsDNA Ab positivity, $\mathrm{n}(\%)$ & $213(65.5 \%)$ \\
\hline SLEDAI (mean \pm s.d.) & $17.4 \pm 5.8$ \\
\hline Class II (\%) & $19(5.8 \%)$ \\
\hline Class III (\%) & $67(20.6 \%)(28 I I+V)$ \\
\hline Class IV (\%) & $178(54.8 \%)(33 \mathrm{IV}+\mathrm{V})$ \\
\hline Class V (\%) & $59(18.2 \%)$ \\
\hline Class VI (\%) & $2(0.6 \%)$ \\
\hline Al score (median; IQR) & $8 ; 4-11$ \\
\hline Endocapillary hypercellularity (median; IQR) & $3 ; 1-3$ \\
\hline Cellular crescents (median; IQR) & $0 ; 0-2$ \\
\hline Karyorrhexis/fibrinoid necrosis ((median; IQR) & $0 ; 0-2$ \\
\hline Subendothelial hyaline deposits (median; IQR) & $1 ; 0-2$ \\
\hline Interstitial inflammatory cell infiltration (median; IQR) & $1 ; 1-2$ \\
\hline Glomerular leukocyte infiltration (median; IQR) & $1 ; 0-1$ \\
\hline Cl score (median; IQR) & $2 ; 2-4$ \\
\hline Glomerular sclerosis (median; IQR) & $0 ; 0-1$ \\
\hline Fibrous crescents (median; IQR) & $0 ; 0-0$ \\
\hline Tubular atrophy (median; IQR) & $1 ; 1-1$ \\
\hline Interstitial fibrosis (median; IQR) & $1 ; 1-1$ \\
\hline Renal microvascular lesions & $267(82.2 \%)$ \\
\hline $\operatorname{ICD}(\%)$ & $240(73.8 \%)$ \\
\hline AS (\%) & $84(25.8 \%)$ \\
\hline TMA (\%) & $58(17.8 \%)$ \\
\hline NNV (\%) & $13(4.0 \%)$ \\
\hline TRV (\%) & $2(0.6 \%)$ \\
\hline
\end{tabular}

Note: ANA, antinuclear antibody; Anti-dsDNA Ab, Anti-double-stranded DNA antibody; SLEDAl, systemic lupus erythematosus disease activity index; Al, activity index; $\mathrm{Cl}$, chronicity index; ICD, immune complex deposits; AS, atherosclerosis; TMA, thrombotic microangiopathy; NNV, noninflammatory necrotizing vasculopathy; TRV, true renal vasculitis; $\mathrm{n}$, number; s.d., standard deviation; IQR, interquartile range.

Table 2. C4d staining pattems in different renal anatomic compartments. 


\begin{tabular}{|llllll|}
\hline & G distribution & G intensity & Arteriole & PTC & TBM \\
\hline Negative & $6(1.8 \%)$ & $6(1.8 \%)$ & $223(68.6 \%)$ & $215(66.2 \%)$ & $183(56.3 \%)$ \\
\hline Minimal & $3(0.9 \%)$ & $37(11.4 \%)$ & $78(24 \%)$ & $90(27.7 \%)$ & $116(35.7 \%)$ \\
\hline Focal & $6(1.8 \%)$ & $88(27.1 \%)$ & $15(4.6 \%)$ & $13(4.0 \%)$ & $21(6.5 \%)$ \\
\hline Diffuse & $310(95.4 \%)$ & $194(59.7 \%)$ & $9(2.8 \%)$ & $7(2.2 \%)$ & $5(1.5 \%)$ \\
\hline
\end{tabular}

Note: G, glomerular; PTC, peritubular capillary; TBM, tubular basement membrane; Minimal, Focal and Diffuse represent the distribution of the C4d staining $<10 \%, 10-50 \%$ and $>50 \%$ respectively.

Table 3. Correlation analysis of C4d deposition in different renal areas with clinical and laboratory data.

\begin{tabular}{|c|c|c|c|c|c|}
\hline & G distribution $(r)$ & $\begin{array}{l}\text { G intensity } \\
\nabla r \rrbracket\end{array}$ & $\begin{array}{l}\text { Arteriole } \\
\text { (r) }\end{array}$ & $\begin{array}{l}\text { PTC } \\
\text { (r) }\end{array}$ & $\begin{array}{l}\text { TBM } \\
(r)\end{array}$ \\
\hline Gender (Female/Male) & 0.022 & -0.049 & -0.053 & -0.082 & -0.078 \\
\hline Age (years) & 0.004 & -0.037 & 0.039 & 0.105 & 0.040 \\
\hline Hematuria & -0.017 & -0.086 & -0.002 & 0.080 & $0.134^{\star}$ \\
\hline Leukocyturia (non-infectious) & 0.030 & -0.027 & 0.020 & -0.019 & $0.177^{\star \star *}$ \\
\hline Urine protein $(\mathrm{g} / 24 \mathrm{~h})$ & 0.097 & $0.159 * *$ & 0.066 & 0.089 & $0.177^{\star}$ \\
\hline Acute kidney injury & 0.108 & -0.054 & 0.060 & 0.060 & $0.183^{*}$ \\
\hline Serum creatinine $(\mu \mathrm{mmol} / \mathrm{l})$ & 0.002 & -0.099 & $0.171^{\star \star}$ & $0.119 *$ & $0.288 * \star$ \\
\hline C3 (g/L) & 0.079 & $0.175^{\star \star}$ & 0.035 & $-0.136 *$ & $-0.149 * \star$ \\
\hline ANA & -0.027 & -0.014 & -0.023 & 0.039 & 0.062 \\
\hline Anti-dsDNA Ab positivity & -0.034 & $-0.115^{\star}$ & -0.037 & 0.073 & 0.046 \\
\hline SLEDAI & 0.050 & -0.090 & 0.008 & 0.101 & $0.190 * *$ \\
\hline
\end{tabular}

Notes: PTC, peritubular capillary; TBM, tubular basement membrane; ANA, antinuclear antibody; Anti-dsDNA Ab, Anti-double-stranded DNA antibody; SLEDAI,

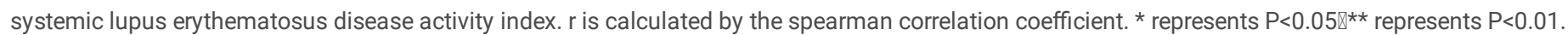

Table 4: Correlation analysis of C4d deposition in different renal areas with histopathological data.

\begin{tabular}{|c|c|c|c|c|c|}
\hline & $\begin{array}{l}\text { G distribution } \\
\text { (r) }\end{array}$ & $\begin{array}{l}\text { G intensity } \\
\text { (r) }\end{array}$ & $\begin{array}{l}\text { Arteriole } \\
\text { (r) }\end{array}$ & $\begin{array}{l}\text { PTC } \\
\text { (r) }\end{array}$ & $\begin{array}{l}\text { TBM } \\
(r)\end{array}$ \\
\hline Al score & 0.048 & -0.103 & $0.126^{\star}$ & $0.131^{\star}$ & $0.323^{* *}$ \\
\hline Endocapillary hypercellularity & 0.037 & -0.089 & 0.102 & 0.067 & $0.292^{\star *}$ \\
\hline Cellular crescents & $0.134^{*}$ & -0.037 & $0.166^{\star \star}$ & $0.114^{\star}$ & $0.365^{\star *}$ \\
\hline Karyorrhexis/fibrinoid necrosis & 0.024 & -0.015 & 0.056 & 0.107 & 0.108 \\
\hline Subendothelial hyaline deposits & 0.028 & -0.048 & 0.027 & 0.107 & 0.093 \\
\hline Interstitial inflammatory cell infiltration & -0.028 & $-0.161 * \star$ & $0.137^{\star}$ & $0.152^{\star \star}$ & 0.260 ** \\
\hline Glomerular leukocyte infiltration & -0.004 & $-0.136^{\star}$ & 0.049 & 0.046 & $0.147^{*}$ \\
\hline Cl score & 0.008 & -0.089 & $0.180 * \star$ & 0.192 ** & $0.293^{\star \star}$ \\
\hline Glomerular sclerosis & 0.052 & 0.003 & $0.127^{\star}$ & $0.121^{\star}$ & 0.101 \\
\hline Fibrous crescents & -0.023 & -0.074 & -0.034 & 0.077 & $0.143^{\star \star}$ \\
\hline Tubular atrophy & -0.033 & -0.102 & $0.204^{\star}$ & $0.192^{\star \star}$ & $0.300 * \star$ \\
\hline Interstitial fibrosis & 0.017 & -0.069 & $0.219 \star \star$ & $0.163^{\star \star}$ & $0.305^{\star \star}$ \\
\hline
\end{tabular}

Notes: Al, activity indices; $\mathrm{Cl}$, chronicity indices.

Table 5. Analysis of co-deposition between arteriolar C4d and C1q, C3c and different immunoglobulins ( $\operatorname{lgG}, \operatorname{lgM}$ and $\lg \mathrm{A})$. 


\begin{tabular}{|c|c|c|c|c|c|c|c|c|c|c|c|c|c|c|}
\hline & $\mathrm{C} 3 \mathrm{c} \rrbracket$ & $\mathrm{C} 3 \mathrm{c} \rrbracket$ & $P$ & $\mathrm{C} 1 \mathrm{q} \otimes$ & $\mathrm{C} 1 \mathrm{q} \otimes$ & $P$ & lgG- & $\operatorname{lgG}+$ & $P$ & IgM- & $\operatorname{lgM}+$ & $P$ & $\lg A \otimes$ & $\lg A X$ \\
\hline Number of patients & 62 & 40 & & 25 & 77 & & 61 & 41 & & 64 & 38 & & 84 & 18 \\
\hline $\begin{array}{l}\text { Al score (median, } \\
\text { IQR) }\end{array}$ & $\begin{array}{l}8(2.75- \\
12)\end{array}$ & $\begin{array}{l}9(6.25- \\
12)\end{array}$ & 0.151 & $\begin{array}{l}8(1.5- \\
11.5)\end{array}$ & $\begin{array}{l}9(5.5- \\
12)\end{array}$ & 0.255 & $\begin{array}{l}8(3- \\
12)\end{array}$ & $\begin{array}{l}9(6.5- \\
12)\end{array}$ & 0.208 & $\begin{array}{l}8(3- \\
11.75)\end{array}$ & $\begin{array}{l}10.5(6- \\
12.25)\end{array}$ & 0.096 & $\begin{array}{l}8(3.25- \\
12)\end{array}$ & $\begin{array}{l}10.5(7 \\
12.25)\end{array}$ \\
\hline $\begin{array}{l}\text { Endocapillary } \\
\text { hypercellularity } \\
\text { (median,IQR) }\end{array}$ & $\begin{array}{l}2.5(1- \\
3)\end{array}$ & $3(2-3)$ & 0.050 & $\begin{array}{l}2(0.5- \\
3)\end{array}$ & $\begin{array}{l}3(2- \\
3)\end{array}$ & 0.071 & $\begin{array}{l}3(1- \\
3)\end{array}$ & $\begin{array}{l}3(2- \\
3)\end{array}$ & 0.297 & $2(1-3)$ & $3(2-3)$ & 0.016 & $2.5(1-$ & $3(3-3)$ \\
\hline $\begin{array}{l}\text { Cellular crescents } \\
\text { (median,IQR) }\end{array}$ & $2(0-2)$ & $2(0-4)$ & 0.118 & $\begin{array}{l}0(0- \\
2)\end{array}$ & $\begin{array}{l}2(0- \\
2)\end{array}$ & 0.493 & $\begin{array}{l}2(0- \\
2)\end{array}$ & $\begin{array}{l}2(0- \\
4)\end{array}$ & 0.096 & $2(0-2)$ & $2(0-4)$ & 0.171 & $2(0-2)$ & $2(0-6)$ \\
\hline $\begin{array}{l}\text { Karyorrhexis/fibrinoid } \\
\text { necrosis } \\
\text { (median,IQR) }\end{array}$ & $0(0-2)$ & $\begin{array}{l}1.5(0- \\
2)\end{array}$ & 0.565 & $\begin{array}{l}2(0- \\
2)\end{array}$ & $\begin{array}{l}0(0- \\
2)\end{array}$ & 0.734 & $\begin{array}{l}1(0- \\
2)\end{array}$ & $\begin{array}{l}0(0- \\
2)\end{array}$ & 0.966 & $0(0-2)$ & $1(0-2)$ & 0.869 & $\begin{array}{l}0.5(0- \\
2)\end{array}$ & $1(0-2)$ \\
\hline $\begin{array}{l}\text { Subendothelial } \\
\text { hyaline deposits } \\
\text { (median,IQR) }\end{array}$ & $1(0-2)$ & $\begin{array}{l}1(0- \\
1.75)\end{array}$ & 0.803 & $\begin{array}{l}0(0- \\
1.5)\end{array}$ & $\begin{array}{l}1(0- \\
2)\end{array}$ & 0.051 & $\begin{array}{l}1(0- \\
2)\end{array}$ & $\begin{array}{l}1(0- \\
1)\end{array}$ & 0.807 & $1(0-2)$ & $1(0-2)$ & 0.224 & $1(0-2)$ & $\begin{array}{l}1(1- \\
2.25)\end{array}$ \\
\hline \multicolumn{15}{|l|}{ Table 5 (Continued) } \\
\hline $\begin{array}{l}\text { Interstitial } \\
\text { inflammatory cell } \\
\text { infiltration } \\
\text { (median,IQR) }\end{array}$ & $1(1-2)$ & $1(1-2)$ & 0.358 & $\begin{array}{l}1(1- \\
2)\end{array}$ & $\begin{array}{l}1(1- \\
2)\end{array}$ & 0.248 & $\begin{array}{l}1(1- \\
2)\end{array}$ & $\begin{array}{l}1(1- \\
2)\end{array}$ & 0.370 & $1(1-2)$ & $1(1-2)$ & 0.052 & $1(1-2)$ & $\begin{array}{l}1(1- \\
2.25)\end{array}$ \\
\hline $\begin{array}{l}\text { Glomerular leukocyte } \\
\text { infiltration } \\
\text { (median,IQR) }\end{array}$ & $1(0-1)$ & $1(1-1)$ & 0.046 & $\begin{array}{l}1(0- \\
1)\end{array}$ & $\begin{array}{l}1(0- \\
1)\end{array}$ & 0.788 & $\begin{array}{l}1(0- \\
1)\end{array}$ & $\begin{array}{l}1(1- \\
1)\end{array}$ & 0.135 & $1(0-1)$ & $1(0-1)$ & 0.811 & $1(0-1)$ & $1(1-1)$ \\
\hline $\begin{array}{l}\text { Cl score (median, } \\
\text { IQR) }\end{array}$ & $\begin{array}{l}2.5(2- \\
4)\end{array}$ & $3(2-5)$ & 0.024 & $\begin{array}{l}2(2- \\
3)\end{array}$ & $\begin{array}{l}3(2- \\
4.5)\end{array}$ & 0.014 & $\begin{array}{l}3(2- \\
4)\end{array}$ & $\begin{array}{l}3(2- \\
5)\end{array}$ & 0.140 & $\begin{array}{l}2.5(2- \\
4)\end{array}$ & $3(2-5)$ & 0.052 & $3(2-4)$ & $\begin{array}{l}3.5(2- \\
5)\end{array}$ \\
\hline $\begin{array}{l}\text { Glomerular sclerosis } \\
\text { (median,IQR) }\end{array}$ & $0(0-1)$ & $1(0-1)$ & 0.396 & $\begin{array}{l}0(0- \\
1)\end{array}$ & $\begin{array}{l}1(0- \\
1)\end{array}$ & 0.191 & $\begin{array}{l}0(0- \\
1)\end{array}$ & $\begin{array}{l}0(0- \\
1)\end{array}$ & 0.793 & $0(0-1)$ & $1(0-1)$ & 0.112 & $0(0-1)$ & $0(0-1)$ \\
\hline $\begin{array}{l}\text { Fibrous crescents } \\
\text { (median,IQR) }\end{array}$ & $0(0-0)$ & $0(0-0)$ & 0.547 & $\begin{array}{l}0(0- \\
0)\end{array}$ & $\begin{array}{l}0(0- \\
0)\end{array}$ & 0.020 & $\begin{array}{l}0(0- \\
0)\end{array}$ & $\begin{array}{l}0(0- \\
0)\end{array}$ & 0.280 & $0(0-0)$ & $0(0-0)$ & 0.820 & $0(0-0)$ & $0(0-0)$ \\
\hline $\begin{array}{l}\text { Tubular atrophy } \\
\text { (median,IQR) }\end{array}$ & $1(1-2)$ & $1(1-2)$ & 0.049 & $\begin{array}{l}1(1- \\
1)\end{array}$ & $\begin{array}{l}1(1- \\
2)\end{array}$ & 0.045 & $\begin{array}{l}1(1- \\
1.5)\end{array}$ & $\begin{array}{l}1(1- \\
2)\end{array}$ & 0.060 & $\begin{array}{l}1(1- \\
1.75)\end{array}$ & $1(1-2)$ & 0.023 & $1(1-2)$ & $1(1-2)$ \\
\hline $\begin{array}{l}\text { Interstitial fibrosis } \\
\text { (median,IQR) }\end{array}$ & $1(1-1)$ & $1(1-2)$ & 0.027 & $\begin{array}{l}1(1- \\
1)\end{array}$ & $\begin{array}{l}1(1- \\
1.5)\end{array}$ & 0.093 & $\begin{array}{l}1(1- \\
1)\end{array}$ & $\begin{array}{l}1(1- \\
2)\end{array}$ & 0.021 & $1(1-1)$ & $1(1-2)$ & 0.072 & $1(1-1)$ & $1(1-2)$ \\
\hline
\end{tabular}

Note: Al, activity indices; $\mathrm{Cl}$, chronicity indices; s.d., standard deviation; IQR, interquartile range.

Table 6. Univariate survival analysis of patients' renal prognosis in lupus nephritis. 


\begin{tabular}{|lllll|}
\hline & & \multicolumn{3}{l}{$95 \%$ Confidence intervals } \\
\hline Sex & Hazard ratio & Lower & Upper & P-Value \\
\hline Age & 0.414 & 0.175 & 0.981 & 0.045 \\
\hline Hypertension & 0.977 & 0.946 & 1.009 & 0.155 \\
\hline Neurological disorder & 0.504 & 0.240 & 1.055 & 0.069 \\
\hline Thrombocytopenia & 1.439 & 0.506 & 4.094 & 0.495 \\
\hline Hemoglobin & 1.012 & 0.483 & 2.120 & 0.974 \\
\hline Serum creatinine & 1.002 & 0.994 & 1.010 & 0.571 \\
\hline Acute renal injury & 1.007 & 1.005 & 1.008 & $<0.001$ \\
\hline proteinuria & 8.097 & 4.031 & 16.263 & $<0.001$ \\
\hline Anti-dsDNA antibodies & 1.046 & 0.960 & 1.140 & 0.300 \\
\hline Glomerular C4d distribution & 0.683 & 0.449 & 1.039 & 0.075 \\
\hline Glomerular C4d intensity & 0.718 & 0.496 & 1.037 & 0.077 \\
\hline TBM C4d deposition & 1.558 & 0.783 & 3.101 & 0.207 \\
\hline Arteriolar C4d deposition & 2.074 & 1.056 & 4.075 & $\mathbf{0 . 0 3 4}$ \\
\hline Arteriolar C4d and C3c deposition & 3.652 & 1.736 & 7.683 & $\mathbf{0 . 0 0 1}$ \\
\hline PTC C4d deposition & 1.045 & 0.522 & 2.093 & 0.901 \\
\hline SLEDAl & 1.017 & 0.961 & 1.077 & 0.555 \\
\hline Al score & 1.181 & 1.090 & 1.280 & $<0.001$ \\
\hline Cl score & 1.371 & 1.205 & 1.559 & $<0.001$ \\
\hline Renal microvascular lesions score & 1.419 & 1.073 & 1.876 & $\mathbf{0 . 0 1 4}$ \\
\hline
\end{tabular}

Note: dsDNA, double-stranded DNA; SLEDA, Systemic Lupus Erythematosus Disease Activity Index; Al, activity indices; Cl, chronicity indices.

Table 7. Multivariate survival analysis of the risk factors for renal outcome in patients with lupus nephritis patients. 


\begin{tabular}{|c|c|c|c|c|}
\hline & \multicolumn{4}{|c|}{ 95\% Confidence intervals } \\
\hline & Hazard ratio & Lower & Upper & P-Value \\
\hline \multicolumn{5}{|l|}{ Multivariate Cox hazard analysis } \\
\hline Sex & 0.289 & 0.109 & 0.767 & 0.013 \\
\hline Age & 0.989 & 0.957 & 1.023 & 0.538 \\
\hline Acute kidney injury & 3.206 & 1.127 & 9.118 & 0.029 \\
\hline Anti-dsDNA antibodies & 1.999 & 0.778 & 5.135 & 0.150 \\
\hline Arteriolar C4d deposition & 2.260 & 1.068 & 4.782 & 0.033 \\
\hline Arteriolar C3c deposition & 2.089 & 0.927 & 4.709 & 0.076 \\
\hline Al score & 1.040 & 0.927 & 1.166 & 0.506 \\
\hline $\mathrm{Cl}$ score & 1.250 & 1.049 & 1.489 & 0.013 \\
\hline \multicolumn{5}{|c|}{ Multivariate stepwise Cox hazard analysis } \\
\hline Acute kidney injury & 5.791 & 2.847 & 11.779 & $<0.001$ \\
\hline $\mathrm{Cl}$ score & 1.298 & 1.122 & 1.502 & $<0.001$ \\
\hline \multicolumn{5}{|l|}{ Multivariate Cox hazard analysis } \\
\hline Sex & 0.302 & 0.114 & 0.803 & 0.016 \\
\hline Age & 0.985 & 0.951 & 1.019 & 0.379 \\
\hline Acute kidney injury & 3.142 & 1.112 & 8.879 & 0.031 \\
\hline Anti-dsDNA antibodies & 2.227 & 0.846 & 5.862 & 0.105 \\
\hline Arteriolar C4d and C3c deposition & 3.681 & 1.519 & 8.921 & 0.004 \\
\hline Al score & 1.054 & 0.940 & 1.183 & 0.369 \\
\hline $\mathrm{Cl}$ score & 1.277 & 1.083 & 1.504 & 0.004 \\
\hline \multicolumn{5}{|c|}{ Multivariate stepwise Cox hazard analysis } \\
\hline Acute kidney injury & 6.646 & 3.224 & 13.701 & $<0.001$ \\
\hline $\mathrm{Cl}$ score & 1.230 & 1.056 & 1.433 & 0.008 \\
\hline Arteriolar C4d and C3c deposition & 2.539 & 1.130 & 5.705 & 0.024 \\
\hline
\end{tabular}

Note: dsDNA, double-stranded DNA; Al, activity indices; $\mathrm{Cl}$, chronicity indices.

\section{Figures}



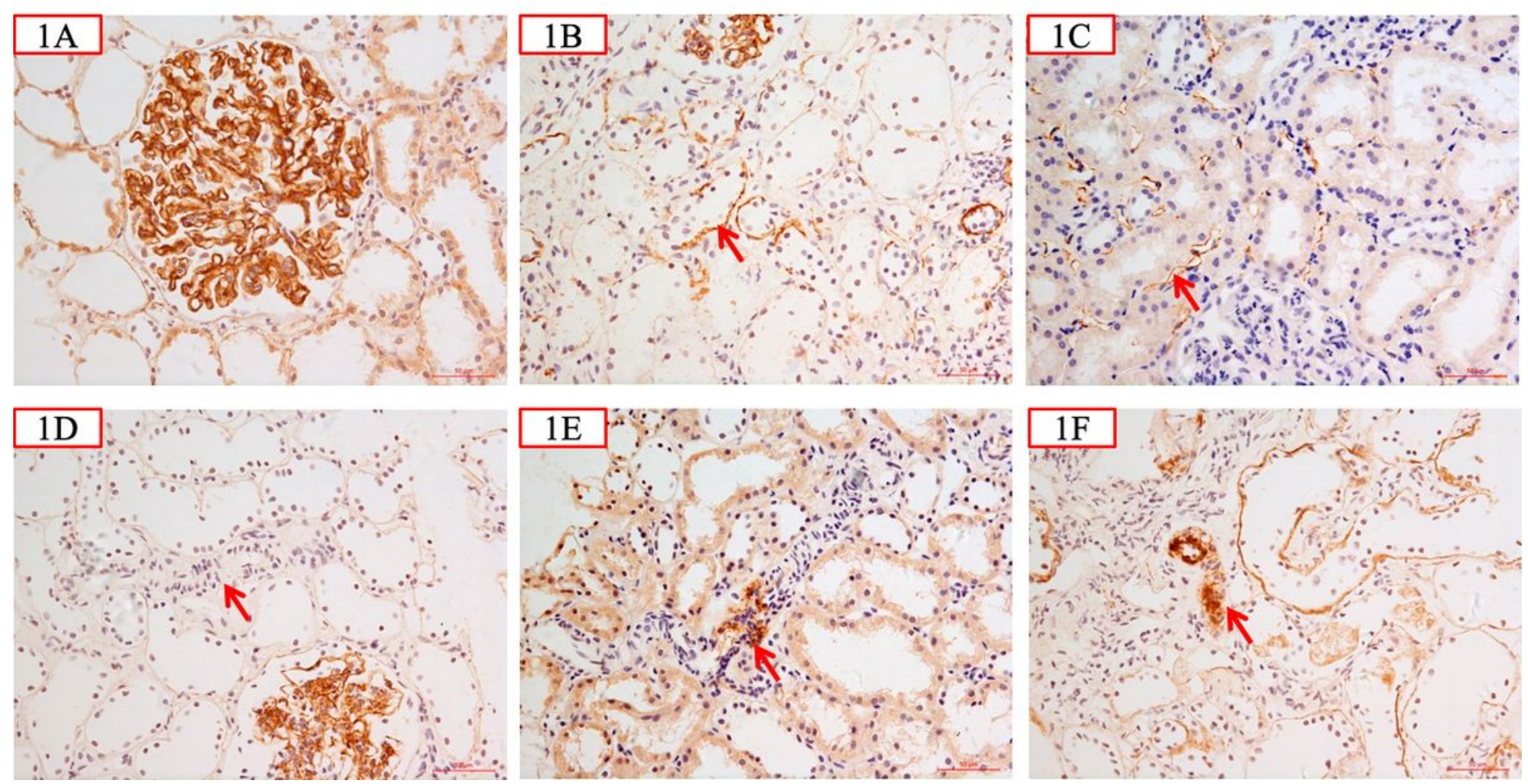

\section{Figure 1}

A showed glomerular C4d granular deposition along the capillary wall and in the mesangial area; B showed C4d deposition along the tubular basement membrane (red arrow); C showed C4d deposition along peritubular capillary wall(red arrow); D showed that C4d was negative in the arteriolar wall (red arrow); E showed C4d segmental arteriolar wall deposition (red arrow); F showed C4d deposition in the arteriolar wall (red arrow); original magnification $\times 400$. 
A
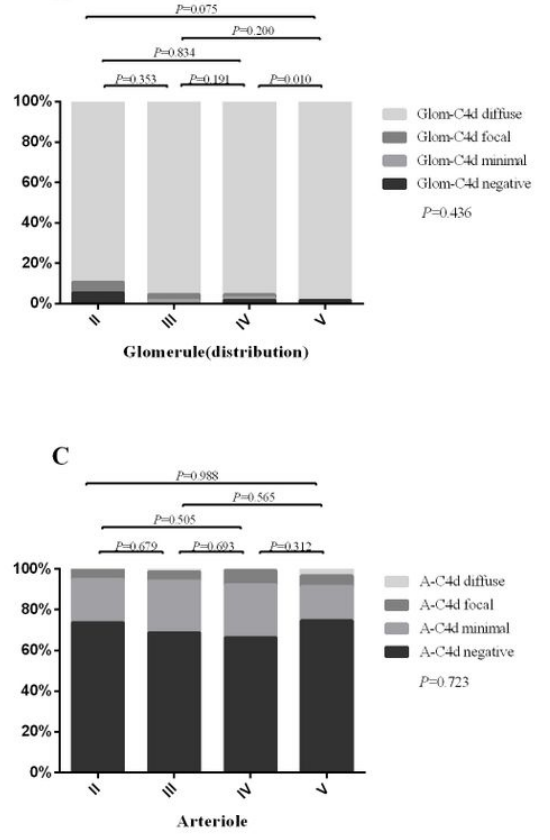

$\mathbf{E}$

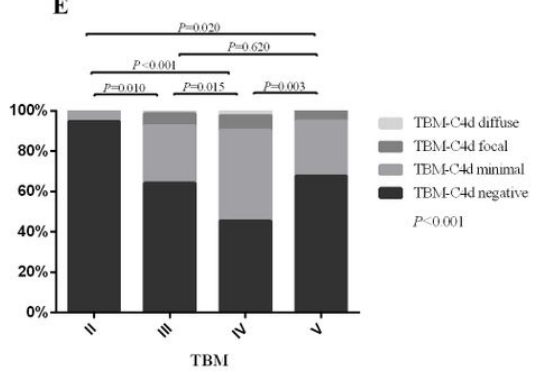

B

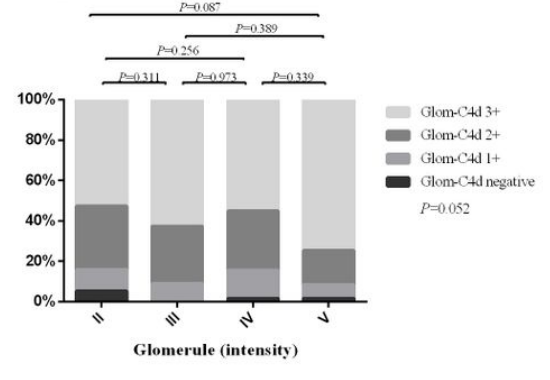

D

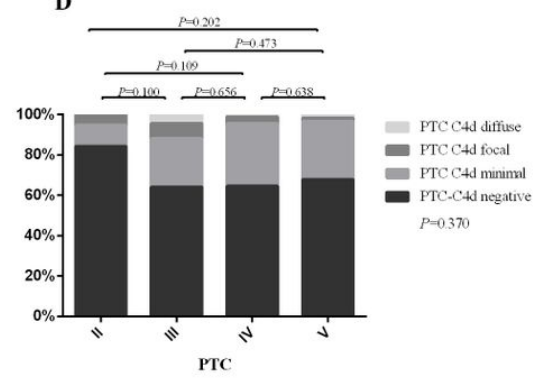

\section{Figure 2}

The distribution or intensity of C4d staining between different lupus nephritis sub-classes. A showed the distribution of glomerular C4d staining; B showed the intensity of glomerular C4d staining; C showed distribution of arteriolar C4d staining; D showed distribution of PTC-C4d staining; E showed distribution of TBM-C4d staining. Abbreviations: Glom, glomerular; A, arteriolar; PTC, peritubular capillary; TBM, tubular basement membrane. 


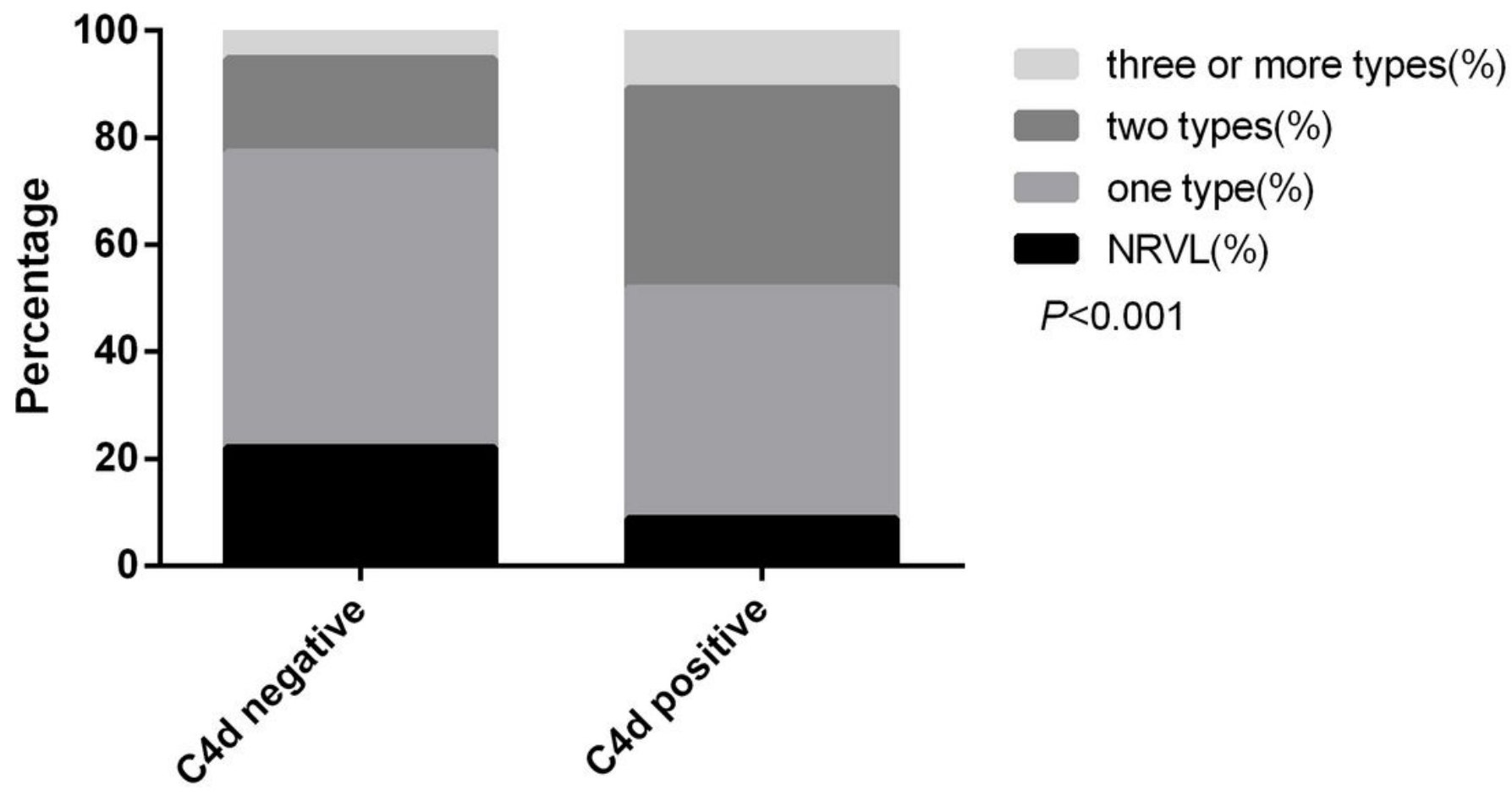

Figure 3

Arteriolar C4d positive patients were more likely to develop renal microvascular lesions compared to those negative. Abbreviations: NRVL, no renal microvascular lesions. 

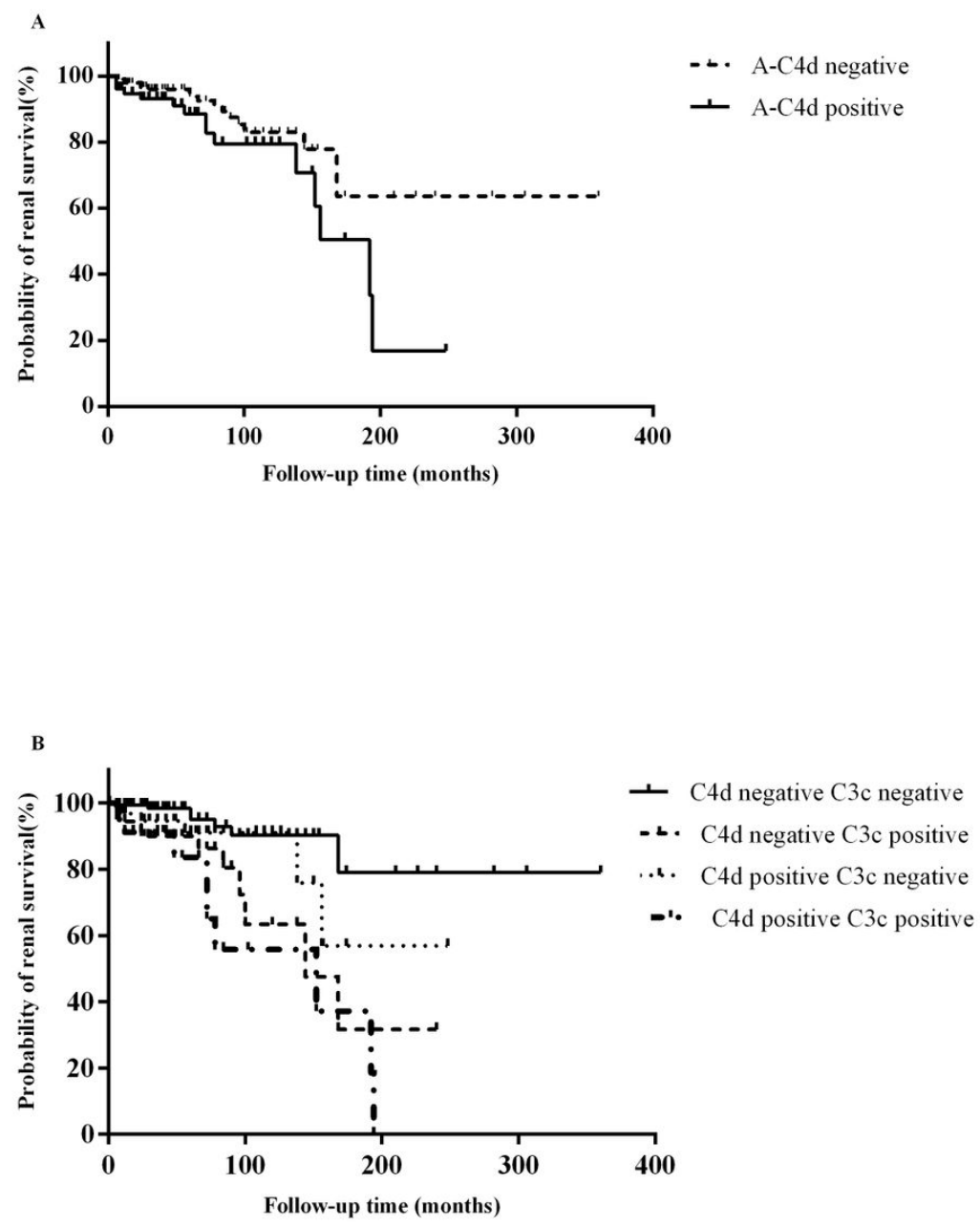

Figure 4

A: Comparison of renal outcomes between patients with and without arteriolar C4d deposition. B: Comparison of renal outcomes between patients with and without arteriolar C4d and C3c deposition. 